\title{
Democracia republicana y autoridad política fiduciaria*
}

\author{
Republican democracy and fiduciary political authority**
}

\author{
ADRIÁN HERRANZ HERRER ${ }^{* * *}$
}

\begin{abstract}
Resumen: En este artículo propongo una justificación de la democracia, y de la autoridad política derivada de ella, a partir del ideal republicano de libertad como no-dominación. Argumento que los procedimientos democráticos tienen valor por sí mismos porque son mecanismos de decisión donde hay libertad de forma recíproca. Ofrezco así una justificación no-instrumental y no-perfeccionista de la participación política. Después muestro que la autoridad debe ser adecuadamente controlada para evitar que exista dominación, razón por la cual tiene que concebirse como una relación fiduciaria, en la que los gobernantes actúan como agentes de la ciudadanía. Finalmente, establezco la necesidad de que los gobernantes cumplan con deberes fiduciarios y que los ciudadanos desarrollen virtudes cívicas.

Palabras clave: Democracia, republicanismo, autoridad política, relaciones fiduciarias, legitimidad.
\end{abstract}

\begin{abstract}
In this article I propose a justification of democracy, and of the political authority derived from it, based on the republican ideal of freedom as non-domination. I argue that democratic procedures have value in themselves because they are decision-making mechanisms where there is freedom on a reciprocal basis. I thus offer a noninstrumental and non-perfectionist justification of political participation. I then show that political authority must be adequately controlled in order to avoid the existence of domination. This is why it must be conceived as a fiduciary relationship, in which the rulers act as agents of the citizenry. Finally, I establish the need for rulers to comply with fiduciary duties and for citizens to develop civic virtues.
\end{abstract}

Key words: Democracy, republicanism, political authority, fiduciary relations, legitimacy.

\section{Introducción: democracia y autoridad política}

Una de las cuestiones centrales de la filosofía política es si existen formas justificadas de autoridad política y, en su caso, qué condiciones deberían cumplir las mismas. En términos generales, la idea es que una autoridad de facto existe cuando hay agentes cuyas directrices otros perciben que tienen la obligación de seguir, mientras que una autoridad es legítima cuando existe una justificación de las obligaciones creadas (Simmons, 2012; Viehoff, 2014;

Recibido: 31/05/2020. Aceptado: 01/07/2020. Cómo citar este articulo: Herranz, A. (2020). Democracia republicana y autoridad política fiduciaria. Daimon. Revista Internacional de Filosofía, (81), 179-195. https:// doi.org/10.6018/daimon.430271

* Este trabajo se enmarca en el proyecto de investigación "Justicia y trabajo: un análisis normativo de formas de trabajo no estándar", ref. PGC2018-095917-A-I00, financiado por el Ministerio de Ciencia, Innovación y Universidades.

** Agradezco los comentarios y sugerencias de Rubén Marciel, Pablo Magaña, Pablo Puertas, Alba Lojo y Victoria Kristan, así como los realizados por los evaluadores anónimos del artículo.

*** Investigador predoctoral en la Universidad Pompeu Fabra. Email: adrian.herranz@upf.edu. Líneas de investigación: filosofía política republicana, democracia económica y sociología del trabajo. 
Christiano, 2018). Otra cuestión central concierne la clase de razones que tenemos para justificar la democracia como modo de gobierno. Cualquier concepción democrática moderna incluye el sufragio universal, pero la definición de democracia está lejos de ser autoevidente. En el sentido más minimalista la democracia se refiere únicamente a la existencia de un sistema competitivo periódico con el que elegir a los gobernantes (Przeworski, 1999). Usando un sentido más amplio, aquí entiendo que la democracia refiere a todos aquellos mecanismos para la toma de decisiones colectivas que implican necesariamente una condición fuerte de igualdad entre los participantes (Christiano, 2018) - una persona un voto, discusión pública, sorteos, referéndums, etc. ${ }^{1}{ }^{1}$. Estipulo (y no todos los autores lo hacen) que, bajo ciertas condiciones, de la democracia se deriva una forma legítima de autoridad.

En este artículo utilizo la filosofía política republicana para ofrecer una respuesta a estas cuestiones. Los republicanos apuntan a un sistema de gobierno donde los ciudadanos tengan libertad entendida como no-dominación (Pettit, 1997, 2012; Skinner, 1998; Domènech, 2019). Argumentaré por qué ese sistema tiene que ser democrático y de qué modo esto contribuye a que la autoridad sea legítima. Después precisaré qué modelo de relación entre ciudadanos y gobernantes es el adecuado a la luz de la teoría republicana, a saber, que al ejercer su autoridad los gobernantes deben actuar como agentes fiduciarios de los ciudadanos. Los gobernantes actúan con cierta discrecionalidad para gestionar los intereses de éstos y por eso las leyes deben establecer mecanismos para que solamente lo hagan bajo su confianza y control. Dicho de otro modo, "el gobierno es un mandato más o menos bien definido, al que los gobernantes deben permanecer fieles, [y] el pueblo está legitimado para pedir cuentas a ese gobierno sobre el alcance y la calidad del uso que éste hace de esa confianza" (Pettit, 1997, 202).

Es importante entender en primer lugar por qué justificamos la autoridad política democrática - las obligaciones generadas por los procedimientos democráticos - , ya que la relación fiduciaria entre ciudadanos y gobernantes es adecuada en la medida en que refleja las razones por las cuales valoramos positivamente ciertas formas de gobierno y su modo de ejercer la autoridad. Dicho esto, una buena forma de plantear la argumentación es distinguir entre:

- Justificación de la autoridad democrática: la autoridad política que deriva de la toma de decisiones democrática es legítima por razones del tipo $x$;

- Constitución fiduciaria de la autoridad democrática: la autoridad se ejerce de acuerdo al rol que le atribuimos en la justificación de la democracia si los gobernantes actúan como agentes fiduciarios de los ciudadanos.

En la sección $2^{\text {a }}$ expongo brevemente dos tipos de justificaciones de la democracia, instrumentales e intrínsecas. En la sección $3^{a}$ reconstruyo la teoría política republicana y ofrezco una justificación intrínseca de la democracia de la cual se deriva la legitimidad de la autoridad política. El artículo ofrece una versión republicana no-instrumental y no-

1 Además del sentido minimalista y del sentido amplio, hay un tercer sentido de procedencia histórica anterior, y de corte más sociológico, como el que empleaba Aristóteles: una democracia es un sistema de gobierno donde la clase social preponderante es el dêmos, el pueblo llano carente de grandes haciendas domésticas y propiedades (Domènech, 2019, cap. 2). 
perfeccionista de la participación política basada en el ideal de la no-dominación. Además, sirve para remarcar ciertas diferencias internas entre los republicanos actuales. En la sección $4^{\mathrm{a}}$ muestro que, para que la justificación republicana que propongo se aplique correctamente en un modelo de democracia, las relaciones entre ciudadanos y gobernantes tienen que ser reguladas como relaciones de agencia fiduciarias.

\section{El valor de la democracia}

Antes de proponer una posición republicana plausible respecto de la autoridad democrática, debo presentar dos tipos básicos de justificaciones de la democracia, las instrumentales y las intrínsecas (Van Parijs, 1996; Anderson, 2009; Christiano, 2018). Las primeras justifican la democracia, y por ende a la autoridad derivada de ella, por producir resultados que consideramos valiosos. Las segundas justifican la democracia por cualidades inherentes al propio procedimiento de toma de decisiones. Nótese que estos dos tipos de justificación refieren a qué tiene valor en la democracia - resultados o procedimientos-, no al modelo concreto de sistema de gobierno. Aquí me limito a exponer en qué sentido los procedimientos democráticos tienen un valor intrínseco y ofrezco razones por las cuales prima facie no podemos prescindir de éste al justificar la democracia.

Para empezar, la existencia de procedimientos adecuados nos indica cómo decidir y quién debe tomar las decisiones, que son condiciones necesarias para establecer la legitimidad de un sistema político (Martí, 2006, cap. 4; Pettit, 2012, cap. 3). Por ejemplo, un dictador eficiente podría proveer generosamente de bienes a los ciudadanos y aun así resultaría más que cuestionable que fuera una autoridad legítima. Por otro lado, como no es razonable esperar acuerdos consensuales constantes entre ciudadanos, tenemos la necesidad de elaborar mecanismos de decisión que sean efectivos pero que también provean a los participantes de una justificación recíproca para aceptar las decisiones (Christiano, 2004, 272 y ss.; Bellamy, 2013, 254-258). El desacuerdo es compatible con mecanismos de decisión que respeten adecuadamente los intereses de los participantes (Rawls, 2002, 51-65). Tanto el pluralismo como la necesidad de acuerdos son consustanciales a las circunstancias de la política y los procedimientos tienen la virtud de vincular a los participantes, de modo que, en las condiciones adecuadas, puedan tomarse decisiones que sean aceptables por todos los implicados.

Es necesario explicitar qué significa que asignemos valor al procedimiento "por sí mismo". Cuando decimos que lo valoramos por sí mismo, estamos diciendo que el tipo de agencia que está implicada en ese procedimiento es valioso. Con otras palabras: valoramos el modo de ser y de decidir constituido por ese procedimiento (Anderson, 2009, 221; Viehoff, 2017, 282). Estas no son afirmaciones especialmente misteriosas, ya que de continuo valoramos tanto el cómo hacemos o decidimos las cosas que hacemos, como el modo de relacionarnos con los demás en ese mismo proceso. Como dice Amartya Sen (2014, cap. 10-11), cuando tomamos una decisión es relevante tener en cuenta qué oportunidades queremos realizar, pero también el proceso por el cual llegamos a tomar la decisión, así como nuestras capacidades implicadas. Dado que en política las decisiones colectivas son vinculantes para todos, el modo de tomar decisiones supone reconocer un tipo de capacidad de acción y un modo particular de relacionarnos con los demás. 
No es necesario negar que pueda haber resultados que son positivos con independencia del procedimiento que valoramos. Del mismo modo, cuando decimos que la amistad tiene un valor intrínseco, lo que estamos diciendo no es que no provea resultados que pueden tener valor instrumental, sino que lo definitorio de la amistad es que valoramos el hecho de relacionarnos como amigos con cierta gente. Valoramos el tipo de persona que somos al ser amigos suyos y la influencia mutua que existe entre nosotros (Domènech, 1993, 52-55). De manera análoga argumentaré que hay algo intrínsecamente valioso en relacionarse como conciudadanos de pleno derecho en una comunidad política democrática.

\section{Republicanismo: una justificación plausible de la autoridad democrática}

La teoría republicana contemporánea puede presentarse como una manera de concretar el contenido de la justificación de la democracia y la autoridad derivada de ella. Según Philip Pettit (2012, 2019), al republicanismo le concierne tanto la dominación horizontal, que puede surgir entre los individuos de una sociedad, como la dominación vertical, que podría ejercer el Estado - o entidad política análoga - sobre los individuos. Hay que precisar que para Pettit ambas cuestiones tienen un significado y requisitos diferentes. La primera refiere a la justicia social y la segunda a la legitimidad (2012, 75-77 y 130-141). La legitimidad se refiere a la aceptabilidad del poder público y de los mecanismos de decisión con los cuales crear o cambiar las normas. Si un régimen político es legítimo tenemos una obligación pro tanto de aceptarlo y, en caso de que existan injusticias sociales, cambiar las cosas de acuerdo al mismo. La justicia social es un ámbito para reclamos más exigentes y exhaustivos sobre la no-dominación entre individuos o sobre la clase de bienes que consideremos que debe proveer un orden social para tratar bien a sus integrantes.

En lo que sigue adoptaré esta distinción entre legitimidad y justicia, centrándome en la primera, para acotar que discuto la justificación normativa que tienen los mecanismos de decisión democráticos. No todos los autores mantienen esta distinción, pues algunos juntan ambas cuestiones al hablar de "universalizar la libertad" (Bertomeu y Domènech, 2005, 66) o de "minimizar la dominación" (Lovett, 2010, cap. 7.3). Al final de la sección propongo una manera de conciliar estas posiciones con la necesidad de diferenciar la cuestión de la legitimidad. Siguiendo a Pettit argumentaré que un régimen político es legítimo si y solo si hay un acceso igualitario a la oportunidad de influir y fijar la dirección de sus decisiones (2012, cap. 3-4), lo cual requiere de una capacidad de agencia robusta por parte de los ciudadanos.

Resumiré la postura republicana como el conjunto de tres tesis interpretadas a partir del ideal de libertad republicana: (I) tesis de la indispensabilidad normativa del poder público, (II) tesis de la conexión entre libertad y democracia, y (III) tesis de la igualdad de poder. Una reconstrucción histórica detallada me llevaría muy lejos, así que me limitaré a presentar una argumentación analítica que es plausible según el ideal de libertad como no-dominación y que, en contra de interpretaciones habituales, supone una justificación intrínseca pero noperfeccionista de la democracia.

Libertad como no-dominación. Según el republicanismo, ser libre significa no estar bajo potestad ajena ni, en general, poder ser interferido por terceros o por el Estado de manera incontrolada (Pettit, 1997, pt. 1, 2012, cap. 1-2; Skinner, 1998, cap. 2; Lovett, 2010, pt. 1; Domènech, 2019, cap. 2). Cuando existe dominación hay una de las partes que tiene que 
plegarse ante las preferencias de terceros, o que realiza sus elecciones gracias al permiso o buena voluntad de éstos. Así, la idea de dominación implica relaciones sociales con asimetrías de poder - donde una parte puede obtener ciertos resultados deseados a pesar de la posible resistencia de la otra parte - y dependencia - donde existen costes de salida a la relación-. Existe dominación siempre y cuando la asimetría de poder y dependencia sean suficientes como para que la parte fuerte pueda obtener la cooperación social de la parte débil y marcar drásticamente la naturaleza de esta cooperación de acuerdo a su voluntad, esto es, de manera incontrolada (McCammon, 2015).

\subsection{Tesis de la indispensabilidad normativa del poder público}

El poder público es el objeto de gran parte de la reflexión republicana porque su existencia es lógicamente anterior a la promoción de la libertad de los ciudadanos:

(I) Tesis de la indispensabilidad normativa del poder público: el poder público es una precondición y una vía de acceso al bienestar o justicia social de la comunidad política.

Por poder público considero un poder coercitivo, monopolístico, difícil de evitar y "final" (Kolodny, 2014, 303-308; González-Ricoy y Queralt, 2018, 618-625). Este último adjetivo hace referencia a que no existe un orden normativo ulterior que decida sobre los aspectos políticos fundamentales. Un poder público con estas características es una precondición para que se provean toda suerte de recursos y derechos (Pettit, 2012, 133), de modo que es una vía de acceso a los mismos. Además, los custodios de este poder son los que podrán garantizarse adecuadamente una protección de sus intereses a partir de esta vía de acceso. Todas estas características justifican que podamos describir al poder público como la fuente última de autoridad de facto. Al actuar como autoridad, generando obligaciones vinculantes, el poder público también sirve para superar problemas de coordinación y de acción colectiva.

La tesis implica que las evaluaciones que hagamos de la comunidad política en cierta medida presuponen que hay un poder público "funcional" - un poder con las características de ser coercitivo, monopolístico, difícil de evitar y final. Como es una tesis normativa, lo que afirma es que para poder establecer un orden político y social que consideremos justo debe existir un poder público. Debemos presuponer que éste existe antes de entrar a considerar otra serie de problemas normativos relevantes.

Podría argumentarse que saboteando la existencia del poder público evitaríamos la dominación vertical de los ciudadanos, pero si hacemos eso perderíamos el mecanismo a partir del cual reducir la dominación horizontal y ya no tendríamos una vía de acceso garantizada a derechos y recursos. Igualmente resultaría problemático que no existiese un poder público porque entonces la autoridad última recaería en otras fuentes, en agentes que, aunque ilegítimamente, de facto podrían arrogarse autoridad sobre otros. Imagínese un Estado que tiene que lidiar con una compañía multinacional cuyos beneficios son superiores a su PIB, que tiene capacidad para dictar sus acuerdos comerciales y constreñir la legislación laboral implementable. En ese caso resulta cuestionable que haya un poder público funcional en manos del Estado, que ya no sería la autoridad última. Es perfectamente posible que la autoridad última sea algo disputado y que esté fuera del alcance de los ciudadanos, pero esto es 
un problema puesto que en ese caso la República no podría determinar y perseguir el bien público (Bertomeu y Domènech, 2005, 74-75).

Una posible objeción a esta tesis es que la definición que doy de poder público es demasiado estrecha porque se refiere únicamente al Estado moderno. Éste se caracteriza por la existencia de una burocracia separada de la sociedad civil, con tareas funcionalmente especializadas y con autoridad central legalmente constituida sobre una población y territorio (Wood, 2012, 8-17). En comparación, la antigua polis de Atenas no tenía un Estado separado de la propia actividad de sus ciudadanos. Pues bien, lo relevante para mi argumento no es que exista un Estado moderno, sino que la propia comunidad política "tenga la última palabra" para fijar obligaciones y garantías, de modo que los individuos disfruten de su libertad por el hecho de ser ciudadanos y no gracias a la buena voluntad de nadie (de este modo, mutatis mutandis la polis u otra entidad política podrían cumplir un papel funcional similar). Esto no obsta a que, para nuestros propósitos, sea relevante hablar del Estado tal y como existe hoy (Richardson, 2002, pt. 3; Pettit, 2012, 160-166). ${ }^{2}$

Asumiendo el valor de la libertad como no-dominación, y dado que según la tesis (I) el poder público es necesario para su promoción, este poder debe ser adecuadamente controlado por los ciudadanos a fin de no convertirse él mismo en un poder dominador. El poder público interferirá irremediablemente en nuestra vida, pero esto no es problemático si está adecuadamente controlado por nosotros, esto es, si la asimetría de poder y la dependencia que puede generar no condiciona la cooperación social a merced de la voluntad de algún agente.

\subsection{Tesis de la conexión entre libertad y democracia}

Según la segunda tesis, los ciudadanos no deberían ver el poder público como algo opuesto o separado de su capacidad de elección en los diferentes aspectos de su vida. Como explica Quentin Skinner (1998, 74 y ss.), los republicanos rechazan la idea de que la libertad empieza "donde calla la ley", más bien se preocupan por quién y por cómo se hace la ley, de modo que no existan poderes discrecionales que actúen a voluntad, esto es, incontrolados por los ciudadanos. Por tanto, podemos asumir la siguiente tesis:

(II)Tesis de la conexión: la libertad personal depende de vivir en una comunidad política que se autogobierna, de ser libre en relación al gobierno del poder público.

Distingo dos interpretaciones republicanas de esta conexión y sitúo históricamente el republicanismo democrático. Ahora podemos volver sobre la discusión de la sección anterior sobre si la democracia tiene valor intrínseco.

Bajo la interpretación instrumental, la democracia es un medio confiable para asegurar la libertad, pero únicamente porque es un mecanismo dirigido a solventar problemas instrumentales bajo constricciones de participación pública, que disminuyen la posibilidad de una Estado autocrático (Rawls, 2002, 194; Elster, 2007, 117-123; Lovett, 2019, 122-129). La

2 Agradezco a un evaluador la sugerencia de precisar este punto. Podría argumentarse también que el poder público se puede articular en un marco federal interestatal o supranacional. 
democracia es una condición pragmática para que la libertad esté más segura, pero no somos libres en tanto que participamos democráticamente. Esta interpretación ha sido atribuida a autores como Pettit y Skinner, a veces denominados como "neo-romanos" (Urbinati, 2012), en contraposición a autores como Pocock o Arendt, que se engloban dentro del humanismo cívico o el neo-aristotelismo. Según la interpretación al uso del concepto de no-dominación que han expuesto los autores neo-romanos, la libertad en el ámbito privado es condicional respecto de poder participar políticamente (Skinner, 1998, 74) 3 . Pretenden que no asimilemos la libertad a una visión perfeccionista de la vida buena - en la que solamente somos excelentes y completos cuando ejercitamos la participación política junto a otros - , ni tampoco a la existencia de una "voluntad general" en la que se tenga que fundir la autonomía individual.

Sin embargo, no me parece necesario asumir la forma condicional de la conexión, como tampoco es necesario asumir la tesis perfeccionista de que la libertad solamente se ejercita en la esfera pública. Arriba señalo que valor intrínseco es aquel valor propio del procedimiento, lo cual no significa que el procedimiento carezca de una justificación acorde a un valor independiente (Viehoff, 2017). El procedimiento tiene valor por sí mismo porque una de sus propiedades es que contribuye a un valor independiente, en este caso la libertad. Si un determinado procedimiento es una forma de interacción libre en el sentido republicano, entonces el propio procedimiento es valioso por sí mismo, porque una de sus propiedades es que constituye relaciones de no-dominación entre ciudadanos.

Como dice Ernst Tugendhat (2008, 123-124), cuando los seres humanos actúan conjuntamente esta acción social depende de la voluntad de los participantes, y entonces la forma en la que se relacionan esos participantes puede caracterizarse como un continuo entre dos posiciones extremas: en la primera posición uno de ellos decide y determina la voluntad del resto, en la segunda, hay una relación de simetría entre las voluntades y la decisión a tomar. Si el procedimiento de decisión sobre el poder público exhibe una simetría como la que menciona Tugendhat, entonces tenemos razones para pensar que este procedimiento constituye una interacción donde hay libertad recíproca, a la par que constituye una comunidad que se autogobierna.

El republicanismo pretende evitar la existencia de poderes incontrolados o arbitrarios y por eso propone la dispersión del poder y una orientación de las decisiones colectivas hacia el bien público. No obstante, hay que precisar que históricamente el republicanismo está desligado de la democracia entendida como membresía universal. Republicanos como Aristóteles o Harrington consideraban que solamente individuos virtuosos con autonomía de juicio debían ser ciudadanos, y pensaban que esta cualidad la tenían las personas con acceso a un determinado estatus social, individuos socialmente independientes con propiedades suficientes como para ganarse la vida sin tener que pedir permiso a terceros (MacGilvray, 2011, cap. 1; Domènech, 2019, cap. 2) ${ }^{4}$. Para adoptar una versión democrática del autogo-

3 Recientemente Pettit ha ido avanzando hacia una conexión definicional entre libertad y democracia: "Sostengo que si partimos de la concepción republicana de la libertad como no dominación, entonces podemos derivar la necesidad de la democracia, bajo una caracterización adecuada, de las exigencias de la libertad" (2012, 22). Según Rostbøll (2015), aunque no es claro que el anterior haya aceptado la interpretación intrínseca, cree que es una interpretación plausible de su obra y una mejor justificación de la autoridad democrática.

4 Así pues, republicanismo y democracia no tienen por qué ir de la mano. Depende de la concepción de la igualdad política adoptada. Esto es útil para interpretar contextos particulares. Por ejemplo, aunque en la Guerra 
bierno republicano tenemos que asumir que todos los miembros plenos de la comunidad deben tener ciudadanía de pleno derecho. ${ }^{5}$ Introduciendo la igualdad política extendemos la ciudadanía republicana. Como argumentan Viehoff (2014) y Kolodny (2014) los procedimientos democráticos tienen una autoridad especial porque excluyen tomar decisiones de modos que subordinen a otros, de ahí que si rechazamos las obligaciones derivadas de tales procedimientos no estamos respetando la igualdad política entre ciudadanos y nos arrogamos un poder especial sobre el resto ${ }^{6}$.

Siguiendo mi versión de la interpretación intrínseca tenemos una teoría basada en la no-dominación en vez del perfeccionismo moral, pero con una conexión entre libertad y democracia más fuerte que la que usualmente se ha atribuido a los autores neo-romanos. Todo ello es más adecuado para un republicanismo democrático que, partiendo de la libertad, enfatice la participación e igualdad políticas.

Justificación de los procedimientos y justificación global. Como he definido la democracia por el tipo de membresía (universal) y por el tipo de mecanismos de decisión colectiva, lo que afirmo es que la membresía y los procedimientos son legítimos considerados aisladamente en tanto que constituyentes de no-dominación. No digo que sean condiciones suficientes para que un individuo sea libre tout court, ni siquiera libre respecto a la dominación vertical. Por tanto, esto no excluye que pueda haber otro tipo de problemas, ajenos a la membresía y el procedimiento, que generen dominación. Tampoco excluye que los modelos concretos de democracia no hagan un uso suficientemente extenso o adecuado de los procedimientos democráticos.

Eso explica por qué las teorías republicanas dan una interpretación más extensiva a los requisitos de la no-dominación respecto del poder público. Así resulta útil distinguir entre la justificación de los procedimientos - discretos, uno a uno- y la justificación global del modelo de democracia - considerando los diferentes procedimientos e instituciones en su conjunto- - . He señalado el valor intrínseco de la democracia al argumentar que los procedimientos son mecanismos de decisión en los que se respeta la libertad de forma recíproca o simétrica. En el siguiente subapartado delineo la justificación global que ofrece la teoría republicana actual. En resumen:

(1) La democracia "facilita" que la autoridad política no domine a los ciudadanos: los procedimientos democráticos - y la membresía universal - constituyen relaciones de no-dominación. [propiedad de la democracia]

(2) La autoridad política es legítima si y solo si evita la dominación (vertical) de los ciudadanos por el poder público. [objetivo republicano]

Civil Inglesa existiese un uso extendido del concepto republicano de libertad, es necesario distinguir entre los autores que oponían el Parlamento timocrático al monarca, de los autores democráticos como los Levellers que a la monarquía oponían "la gente fuera del Parlamento" (Wood, 2012, 227-230). Ver también Urbinati (2012, 608-610). Agradezco a los evaluadores la sugerencia de desarrollar este punto.

5 Queda por discutir quién exactamente es "miembro pleno", aunque podemos decir que habrá una presunción a favor de los residentes habituales, adultos, en pleno uso de sus facultades.

6 No obstante, estos autores creen que la no-subordinación es un valor distinto y menos exigente que la no-dominación (Viehoff, 2019). 
(3) Los procedimientos democráticos son justificados por constituir relaciones de nodominación. (por 1 y 2) [justificación de los procedimientos]

(4) La autoridad política democrática es legítima cuando los procedimientos facilitan la no-dominación hasta el punto de evitar que exista dominación por el poder público. (por 1 y 2) [justificación global]

\subsection{Tesis de la igualdad de poder}

Como no puedo detallar el modelo de democracia del republicanismo voy a esbozar una última tesis sobre la dirección a la que debe apuntar ese modelo. Como dice Pettit (2012, cap. 3-4), un Estado legítimo concede a todos los ciudadanos un acceso igualitario a la oportunidad de influir y fijar la dirección de sus decisiones. Por eso en una democracia republicana tiene que existir una igualdad de poder en el estatus de ciudadanía suficiente como para que los ciudadanos tengan la opción de influir y fijar tal dirección:

(III) Tesis de la igualdad de poder: los ciudadanos deben disfrutar un estatus de ciudadanía que iguale su poder al punto de que ningún agente domine al resto en el proceso de controlar el poder público.

Según la libertad republicana no es tan relevante que puntualmente puedan obtenerse ciertos resultados o realizarse ciertas elecciones, pues pueden deberse a que estemos intimidados o congraciados con agentes poderosos de los que dependemos, cuanto que tengamos una capacidad de agencia robusta en relación al poder público (Pettit, 2012, 60-67; Rostbøll, 2015, 433). Dicho con Pettit (2012, caps. 3.4, 4.3), tiene que existir un control efectivo, incondicionado e individualizado del poder público: El estatus de ciudadanía tiene que guardar a cada ciudadano de que el poder público sea acaparado, manipulado o dirigido por alguna facción o entidad privada (no habría un control efectivo), o que sea administrado a voluntad por el gobierno y sus agencias (no habría un control incondicionado), o que sea abusivo con algún individuo al que se le estaría privando de un estatus igual (no habría un control individualizado). Cabe precisar que, aunque en la justificación global podemos establecer umbrales mínimos de legitimidad para aceptar ciertas instituciones y autoridades, la legitimidad del poder público es una cuestión de grado.

Podemos distinguir tres interpretaciones de la tesis según el tipo de interferencia incontrolada que principalmente se pretende evitar: Pettit $(1997,2012,2019)$ ha argumentado que los ciudadanos pueden influir adecuadamente en un régimen de constitución mixta, donde existe también la posibilidad de disputar las decisiones públicas gracias a una ciudadanía contestataria - evitar la arbitrariedad del poder público-. Según McCormick (2019), teniendo en cuenta la expansión reciente de la desigualdad económica, las instituciones deberían estar diseñadas para mitigar la influencia política de los opulentos - evitar el control del poder público por agentes privados - . Por eso propone reintroducir mecanismos propios del Mediterráneo Antiguo, como el sorteo o alguna suerte de "tribuno de la plebe".

Otros autores han enfatizado que el estatus de los ciudadanos requiere de un mínimo económico individualmente garantizado a todos - evitar que la dependencia distorsione la igualdad política-(Domènech, 2002, 37 y ss.; White, 2011, 565 y ss.; Casassas y de 
Wispelare, 2016, 285-290). Siguiendo la mencionada distinción de Pettit entre legitimidad y justicia, podría objetarse que cuando hablamos de la legitimidad de la democracia y la autoridad estamos concernidos únicamente con la aceptabilidad de los mecanismos de decisión, mientras que estos autores introducen consideraciones relativas a la justicia social. No obstante, aunque aceptemos la distinción y estemos analizando únicamente el control del poder público, si nos preocupa garantizar una capacidad de agencia robusta respecto del mismo entonces parece plausible que deba haber un mínimo suficiente de independencia socioeconómica de unos individuos respecto de otros. Por ejemplo: si un individuo $\mathrm{X}$ es dependiente del poder de $\mathrm{Y}$, entonces $\mathrm{X}$ puede verse inclinado a fiarse de la gente o decisiones que cree que representan los intereses de $\mathrm{Y}$, de modo que su capacidad de decisión no se corresponderá con un control efectivo, incondicionado e individualizado.

Si esta argumentación es válida, se podría asumir simultáneamente que: (i) siguiendo a Pettit la legitimidad es una cuestión distinta de la justicia social; (ii) pero la diferencia entre ambas es menos fuerte que la que él plantea, ya que hay cierto solapamiento entre ambas, debido a que estamos más dispuestos a aceptar procedimientos de decisión que operan bajo un trasfondo de justicia mínima entre los ciudadanos?. Con esta propuesta "intermedia" no espero tanto ofrecer una solución definitiva como clarificar la divergencia que hay entre autores republicanos.

\section{Autoridad política fiduciaria}

Al nivel más abstracto la justificación republicana indica qué propiedades debe tener un modelo legítimo de democracia y de autoridad. Para concretar más el modelo debemos proponer diseños institucionales que exhiban en el mayor grado las propiedades deseadas. En ese sentido la teoría republicana concibe el ejercicio de la autoridad como una relación fiduciaria, lo cual señala un ideal regulativo sobre los límites y deberes de la misma ${ }^{8}$. Muestro que en este esquema fiduciario hay que presuponer que, en las condiciones adecuadas, los ciudadanos pueden desarrollar virtudes cívicas que deben ser estimuladas por el legislador.

\subsection{Relaciones fiduciarias y legitimidad}

En relaciones fiduciarias, originalmente referidas al derecho civil, tenemos dos partes implicadas, el principal (p. ej. los ciudadanos), que encarga una cierta tarea a la segunda parte, el agente (p. ej. los gobernantes), encargada de realizar tal mandato. En comparación con relaciones contractuales al uso, donde el consentimiento previo sobre el contrato establece las condiciones de cumplimiento y las obligaciones ulteriores, éstas son relaciones de agencia, donde las condiciones no pueden especificarse exhaustivamente de antemano. Dicho de otro modo, "la información sobre la cantidad y la calidad del bien o servicio

7 Además, podrían añadirse razones diferentes a las consideradas aquí, por ejemplo, razones relativas a la calidad epistémica de las decisiones.

8 Cuando hablamos de la "autoridad de la democracia" nos referimos a las obligaciones vinculantes derivadas de los procedimientos democráticos. En ese sentido los ciudadanos actúan también como determinantes de la autoridad. Pero al hablar de las relaciones fiduciarias, me remitiré principalmente a los gobernantes electos como creadores de obligaciones. 
proporcionado en un intercambio es asimétrica o no verificable, es decir, no es conocida por ambas partes, o incluso si es conocida no puede ser utilizada en los tribunales para hacer cumplir un contrato" (Bowles, 2016, 32). Así pues, el principal encarga una tarea, de cuyo cumplimiento se va a beneficiar, a un agente, con el problema de que las condiciones de ese cumplimiento no pueden establecerse exhaustivamente de antemano y deben ser controladas y fiscalizadas a posteriori, con el riesgo de que existan comportamientos oportunistas por parte del agente 9 .

Antoni Domènech $(2019,243-254)$ argumenta que las asimetrías de información de las relaciones de agencia - dificultad de estimar el cumplimiento de la tarea, de controlar las acciones del agente, $\mathrm{o}$ de tener la pericia necesaria para comprender el proceso- justifican una protección igualmente asimétrica del principal. Si el principal y el agente son tratados como individuos igualmente libres, entonces cabe pensar que el principal es la parte débil, que requiere de protección legal adicional para prevenir el oportunismo del agente. Por ejemplo, Domènech menciona las cláusulas de buena fe o los códigos deontológicos, que regulan las conductas permisibles del agente. Además, el principal puede emitir nuevas instrucciones sobre la marcha, o retirarle su confianza al agente, despidiéndolo (2019, 246-247).

En definitiva, podemos definir una relación de agencia fiduciaria o fideicomiso como aquella relación de agencia en la que el principal está institucionalmente protegido de forma asimétrica o unilateral, para permitir el adecuado cumplimiento de la tarea encomendada al agente.

Si nos ceñimos a la relación con los gobernantes podemos decir lo que sigue: Ningún sistema en el que los ciudadanos tengan que controlar a los gobernantes puede funcionar sin plantear situaciones de agencia como las mencionadas. Las autoridades tendrán un "mandato" sobre sus funciones, pero necesariamente actuarán con cierto margen de discrecionalidad para poder adaptarse a circunstancias que no pueden anticiparse completamente con anterioridad (Pettit, 1997, cap. 6). Por tanto, el agente gestiona los intereses del principal con cierto margen de discrecionalidad, lo cual crea una potencial vulnerabilidad para este último que justifica un diseño legal-institucional dirigido a mantener la confianza del principal en que el agente actúa para su beneficio (Criddle, 2017). Gracias a la argumentación previa sabemos por qué debemos proteger al principal, estableciendo deberes que limitan el ejercicio legítimo de la autoridad: la discrecionalidad es una fuente potencial de dominación porque puede alterar la influencia de los ciudadanos sobre el poder público.

Para que exista una relación fiduciaria puede existir consentimiento, pero no es una condición necesaria (Fox-Decent, 2005, 287 y ss.). Es suficiente que un agente tenga discrecionalidad para gestionar los intereses de terceros, generando una asimetría de poder y dependencia que debe ser adecuadamente controlada. Por eso, en contra de ciertas posiciones (Simmons, 2012), resulta erróneo basar la legitimidad de la autoridad en el consentimiento. Como dice Viehoff, el consentimiento es problemático porque si alguien "puede rechazar libremente el resultado del procedimiento, o rehusarse a dejar que ese procedimiento resuelva el asunto, puede aprovechar su poder y esperar a tener una mejor posición" (2014,

9 Podría haber tres partes: un principal, un beneficiario distinto de éste y un agente. Aquí simplifico la situación y entiendo que los ciudadanos son el principal (y el beneficiario) y los gobernantes el agente. 
370). Por eso los Estados o entidades análogas no son asociaciones voluntarias ni pueden llegar a serlo en ninguna circunstancia, ya que dejarían de ser autoridades últimas.

La idea de relaciones fiduciarias nos permite delimitar más claramente cómo debe ser el desempeño de la autoridad. El mandato de la autoridad no debe entenderse como una mera delegación en la que tenemos que contar con la buena fe de los gobernantes. Puesto que el ejercicio de la autoridad tiene márgenes de discrecionalidad tampoco es adecuado entender que los gobernantes tienen unas instrucciones perfectamente delimitadas que deben seguir al pie de la letra. Las relaciones fiduciarias ocupan un término medio conceptual entre la delegación completa y el mandato imperativo.

Aunque la autoridad cumpla con ciertos objetivos elementales (garantizar la coordinación a gran escala, superar problemas de acción colectiva o repartir recursos y derechos), su legitimidad depende de su conexión con la influencia popular. Para el republicanismo, la concepción fiduciaria de la autoridad se deriva de la necesidad de que el poder público sea democráticamente controlado por los ciudadanos. Éstos tienen una obligación de cumplir con las directrices de la autoridad democrática en la medida en que disfrutan de un acceso igualitario a la oportunidad de influir y fijar la dirección de sus decisiones. Para que efectivamente puedan "fijar la dirección de sus decisiones" tiene que haber una regulación que asegure la confiabilidad de los gobernantes, a partir de ciertos deberes que limiten y orienten su capacidad de decisión.

\subsection{Deberes fiduciarios}

Se ha señalado que la idea de autoridad fiduciaria fue usada en la filosofía y en la política modernas como un ariete contra las monarquías absolutas, arguyendo que el poder puede volver a sus legítimos poseedores, los ciudadanos, que conservan un derecho a la rebelión (Mundó, 2017, 48-52). Así mismo, se entendía que los cargos debían ser electos, revocables, dispersados según la función que cumplían y responsables ante los ciudadanos (Laín, 2020, 22-24). Una tarea pendiente es estipular con más detalle, y en relación a condiciones actuales, un ideal regulativo sobre la clase de protección unilateral que debe recibir el principal, estableciendo los deberes a los que están sujetas las autoridades electas. En este punto no hay una lista canónica, así que entresaco cuatro tipos de deberes de la literatura sobre relaciones fiduciarias y responsabilidad (accountability) de los gobernantes:

Lealtad. Las autoridades tienen un deber estricto de evitar conflictos de interés y de atenerse a su función pública (Fox-Decent, 2005; Criddle, 2017). Esto justifica que en la esfera pública debamos tener un nivel de exigencia muy superior al que usualmente atribuimos al hablar de responsabilidades legales. Por ejemplo, las quejas sobre las "puertas giratorias" son razonables porque señalan un modo de permitir influencias espurias en los agentes del poder público, que hacen que los políticos no sean "servidores" fieles de su rol como gobernantes. Además, el ejercicio del cargo debe estar sometido a estándares públicos que regulen su ejercicio (Pettit, 2019, 35-38), de modo que la autoridad no puede ejercerse caprichosamente sino de modos que razonablemente puedan ser aceptados según la cultura política democrática (Anderson, 2009, 214-218). Los cargos deben ser una carga onerosa.

Publicidad. También podemos presumir que la actividad política se realiza de cara al público y que existen canales adecuados para que la opinión pública esté informada de los 
aspectos políticos relevantes (Richardson, 2002, caps. 10, 13; Ponet y Leib, 2011, 1255 y ss.; Pettit, 2012, 215 y 233-235). El alcance de este deber para con la ciudadanía es muy amplio, pues implica que todos tienen acceso a fuentes fiables de información, pero también que los gobernantes deben actuar transparentemente, de buena fe y exponiéndose de forma periódica a dar explicaciones de sus actos. Acorde a este deber podemos hablar de un derecho a la información por parte de la ciudadanía, según el cual la información política relevante debe estar disponible, sujeta a condiciones de veracidad y sin monopolizarse por poderosos agentes privados.

Responsividad. Los agentes son "responsivos" si están atentos y son considerados con las indicaciones del principal (Przeworski, Stokes, y Manin, 1999; Pettit, 2012, cap. 4). Sería problemático entender este deber como la acción de reflejar directamente las preferencias de los ciudadanos, por los diferentes problemas que tiene la mera agregación de preferencias (Sen, 2014, 339-344). Más bien, los republicanos suelen favorecer que las instituciones fomenten y sean sensibles a la deliberación pública (Richardson, 2002; Martí, 2006). A ese respecto existen diseños institucionales como los minipublics o los presupuestos participativos (Fung, 2003) que pueden permitir las consultas o incluso las decisiones directas de los ciudadanos. De manera más radical, podemos tomar la idea de Jefferson sobre la necesidad de una revisión constitucional periódica para dar cabida a las diferentes generaciones.

Responsabilidad. Finalmente, los gobernantes deben rendir cuentas ante los ciudadanos, pudiendo ser premiados o castigados por ellos (Przeworski, Stokes, y Manin, 1999; De Francisco, 2003; Bovens, Goodin y Schillemans, 2014). Obviamente las elecciones periódicas cumplen de forma mínima este deber - denegando o permitiendo la reelección-, pero parece un requisito insuficiente. Por otro lado, resulta problemático diseñar mecanismos efectivos con los que fiscalizar y sancionar a los gobernantes en sociedades contemporáneas. Una forma plausible e indirecta de hacer responsables a los gobernantes es fragmentar su poder y dificultar su mantenimiento a lo largo del tiempo, a la vez que incrementamos el uso de mecanismos democráticos a partir de las cuales los gobernantes adquieren autoridad. Por ejemplo, hacer que los cargos sean de corta duración, que tengan atribuciones acotadas y que sean contrapesadas por otras autoridades, pero también, hacer que los cargos sean dependientes de organizaciones o asambleas con un funcionamiento democrático, o introduciendo medidas como sorteos en la elección de cargos orgánicos dentro de los partidos políticos para evitar las inercias burocráticas.

Conviene mencionar que existe una mutua dependencia entre los diferentes deberes. La lealtad con el principal se verá enriquecida si existen inputs desde la deliberación pública. Sin medios para controlar la autoridad la "responsividad" no será tan eficiente porque los gobernantes carecerán de controles externos que les empujen a considerar a sus electores. Tampoco resulta plausible que la responsabilidad ciudadana pueda ejercerse sin publicidad, sin conocerse bien la información políticamente relevante.

\subsection{Instituciones republicanas y virtud cívica}

Finalmente, si aceptamos que la autoridad debe ser confiable, hay que notar que toda teoría republicana debe presuponer cierto grado de circularidad entre (buenas) instituciones y (buenos) ciudadanos. Sin entrar en detalles, podemos centrarnos en relaciones unidirec- 
cionales ("las leyes hacen buenos ciudadanos" o "los ciudadanos controlan el buen funcionamiento de las leyes") o bidireccionales ("las leyes y los ciudadanos coevolucionan"). Esta circularidad reintroduce en el debate la idea de virtud cívica.

Las virtudes cívicas son la pluralidad de disposiciones o motivaciones psicológicas prosociales que son relevantes para tener interés en la esfera pública, para desarrollar una cultura pública democrática y para cumplir reflexivamente con las normas del poder público ${ }^{10}$. Para seguir la línea del artículo, podemos acotar más y tratar "la virtud cívica como la motivación causalmente eficiente hacia la acción públicamente orientada" (Tena, 2010, 318-321), definiendo la orientación pública en términos de reducción de la dominación y búsqueda de la igualdad política. En un paso subsiguiente habría que observar qué clase de motivaciones están especialmente bien dispuestas para causar este tipo de acciones y de qué modo pueden estimularse, o al menos no obstaculizarse, con el diseño institucional. Por ejemplo, la "reciprocidad fuerte", que es la motivación a cooperar condicionalmente con otros incluso con costes para uno mismo y con disposición a castigar incumplimientos, está asociada a la equidad o equilibrio en la asunción de obligaciones y beneficios sociales (Bowles y Gintis, 2000, 44-47), lo que la hace adecuada para promover la igualdad política del planteamiento republicano-democrático.

Ciudadanos virtuosos generan un entorno de instituciones confiables, puesto que estarán dispuestos a reprender el incumplimiento de las normas - p. ej. los deberes fiduciarios - y la falta de consideración debida al estatus de algunos ciudadanos. Esta apreciación es una generalización al espacio público de disposiciones conductuales probadas experimentalmente: Cuando individuos que deben cooperar tienen a su disposición castigos para los incumplidores y pueden deliberar antes de tomar decisiones, entonces todos son más propensos a cooperar y por tanto los resultados globales son mejores que si fueran autointeresados (Bowles, 2016, 196-200).

Por eso las relaciones fiduciarias implican la existencia de virtudes, ya que la confiabilidad de la autoridad, el agente, solamente puede definirse con referencia a un principal que está dispuesto a actuar para mantener a raya al poder público. A su vez, sin las instituciones adecuadas los ciudadanos no podrán canalizar su voz de un modo que se mantenga su acceso igualitario a la influencia sobre el poder público. Ésta es la lección para el legislador republicano: Si la autoridad se regula como una relación fiduciaria entonces hay que diseñar normas e instituciones "sesgadas" hacia los ciudadanos, facilitando su participación en la esfera pública, haciendo que sus decisiones sean efectivas, pero así mismo presumiendo que hay virtudes cívicas que pueden ser espoleadas bajo ciertas normas. A este respecto, es relevante considerar que la interpretación socioeconómica de la igualdad de poder puede proporcionar las oportunidades de ocio, y puede conferir la independencia respecto de terceros, que son necesarias para el cultivo de las virtudes cívicas (Domènech, 1993, 2019, cap. 2; Bertomeu y Domènech, 2005, 74).

\section{Conclusión}

Al inicio del artículo he argumentado que tenemos razones para pensar que la justificación de la democracia tiene que hacer referencia al valor intrínseco de los procedimientos. Ciertos procedimientos tienen la propiedad de hacernos decidir y relacionarnos con los

10 Para ver diferentes concepciones de la virtud cívica que no puedo discutir aquí véase Pettit, 1997, cap. 8; Peña, 2005; Tena, 2010; MacGilvray, 2011, cap. 1. 
demás de formas que valoramos. Luego he propuesto una justificación intrínseca y noperfeccionista basada en una reconstrucción plausible de la teoría republicana. Según esta concepción debemos presuponer un poder público funcional que debe estar diseñado para evitar la dominación de los ciudadanos. Los procedimientos democráticos son, individualmente considerados, ejemplos de mecanismos para elegir de forma recíproca en libertad y de ahí deriva su autoridad normativa. No obstante, usualmente lo que nos preocupa es la "justificación global" de los modelos de democracia, en los cuales diferentes instituciones y mecanismos de decisión interactúan. Aquí el republicanismo se guía por el criterio de la igualdad de poder de estatus a la hora de influir en el poder público, aunque no todos los autores lo interpretan igual. Este punto abre un debate interesante que merece un mayor desarrollo. Por último, si entramos a precisar el modo legítimo de ejercer la autoridad por los gobernantes, éstos deben actuar como agentes fiduciarios, dada la existencia de un poder discrecional para administrar los intereses de los ciudadanos. Esta asunción reconoce implícitamente que los ciudadanos pueden desarrollar virtudes cívicas. De esta manera estamos en condiciones de explicar por qué el poder político es una cesión temporal y constreñida legalmente, pero no dependiente del consentimiento individual, a la vez que entendemos mejor la clase de dificultades y objetivos que enfrenta el legislador republicano.

\section{Bibliografía}

Anderson, E. (2009), «Democracy: Instrumental vs. Non-Instrumental Value», en: T. Christiano y J. Christman (eds.): Contemporary Debates in Political Philosophy, Malden: Blackwell Publishing, pp. 213-228.

Bellamy, R. (2013), «Rights, Republicanism and Democracy», en: A. Niederberger y P. Schink (eds.): Republican Democracy. Liberty, Law and Politics, Edinburgh: Edinburgh University Press, pp. 262-285.

Bertomeu, M. J. y Domènech, A. (2005), «El republicanismo y la crisis del rawlsismo metodológico (Nota sobre método y sustancia normativa en el debate republicano)», Isegoría, 33, pp. 51-75.

Bovens, M., Goodin, R. y Schillemans, T. (2014), «Public Accountability», en: M. Bovens, T. Schillemans y R. Goodin (eds.): The Oxford handbook of public accountability, Oxford: Oxford University Press, pp. 182-208.

Bowles, S. (2016), The Moral Economy. Why incentives are not substitutes for good citizens, Londres: Yale University Press.

Bowles, S. y Gintis, H. (2000), «Reciprocity, Self-Interest, and the Welfare State», Nordic Journal of Political Economy, 26, pp. 33-53.

Casassas, D. y de Wispelare, J. (2016), «Republicanism and the political economy of democracy», European Journal of Social Theory, 19 (2), pp. 283-300.

Christiano, T. (2004), «The Authority of Democracy», The Journal of Political Philosophy, 12 (3), pp. 266-290.

Christiano, T. (2018), «Democracy», Stanford Encyclopedia of Philosophy. https://plato. stanford.edu/archives/fall2018/entries/democracy/.

Criddle, E. J. (2017), «Liberty in loyalty: A republican theory of fiduciary law», Texas Law Review, 95 (5), pp. 993-1060. 
De Francisco, A. (2003), «Para forzar a los gobiernos a responder», en: M. J. Bertomeu, A. Domènech, y A. De Francisco (eds.): Republicanismo y democracia, Madrid: Miño y Dávila, pp. 69-90.

Domènech, A. (1993), «... y fraternidad», Isegoría, 17, pp. 49-77.

Domènech, A. (2002), «Individuo, comunidad y ciudadanía», en: J. Rubio, J. M. Rosales, y M. Toscano (eds.): Retos pendientes en ética y política, Madrid: Trotta, pp. 27-42.

Domènech, A. (2019), El eclipse de la fraternidad. Una revisión republicana de la tradición socialista, Madrid: Akal.

Elster, J. (2007), «El mercado y el foro: tres formas de teoría política», Cuaderno Gris, 9, pp. 103-126.

Fox-Decent, E. (2005), «The Fiduciary Nature of State Legal Authority», Queen's Law Journal, 31, pp. 259-310.

Fung, A. (2003), «Survey article: Recipes for public spheres: Eight institutional design choices and their consequences», Journal of Political Philosophy, 11 (3), pp. 338-367.

González-Ricoy, I. y Queralt, J. (2018), «Political liberties and social equality», Law and Philosophy, 37 (6), pp. 613-638.

Kolodny, N. (2014), «Rule Over None II : Social Equality and the Justification of Democracy», Philosophy and Public Affairs, 42 (4), pp. 195-229.

Laín, B. (2020), «Del derecho natural al pacto fiduciario: gobierno y propiedad en la economía política republicana», Isegoría, 62, pp. 9-34.

Lovett, F. (2010), A General Theory of Domination and Justice, Oxford: Oxford University Press.

Lovett, F. (2019), «Republicanism and Democracy Revisited», en: Y. Elazar y Ge. Rousselière (eds.): Republicanism and the Future of Democracy, Cambridge: Cambridge University Press, pp. 117-129.

MacGilvray, E. (2011), The Invention of Market Freedom, Cambridge: Cambridge University Press.

Martí, J. L. (2006), La república deliberativa, Barcelona: Marcial Pons.

McCammon, C. (2015), «Domination : A Rethinking *», Ethics, 125 (4), pp. 1028-1052.

McCormick, J. P. (2019), «The New Ochlophobia?», en: Y. Elazar y Ge. Rousselière (eds.): Republicanism and the Future of Democracy, Cambridge: Cambridge University Press, pp. 130-151.

Mundó, J. (2017), «La constitución fiduciaria de la libertad política. (Por qué son importantes las coyunturas interpretativas en la filosofía política )», Isegoría, 57, pp. 39-60.

Peña, J. (2005), «Ciudadanía republicana y virtud cívica», en: M. J. Bertomeu, A. Domènech, y A. De Francisco (eds.): Republicanismo y democracia, Madrid: Miño y Dávila, pp. 231-256.

Pettit, P. (1997), Republicanism. A Theory of Freedom and Government, Oxford: Oxford University Press.

Pettit, P. (2012), On the people's terms. A Republican Theory and Model of Democracy, Cambridge: Cambridge University Press.

Pettit, P. (2019), «The General Will, the Common Good, and a Democracy of Standards», en: Y. Elazar y Ge. Rousselière (eds.): Republicanism and the Future of Democracy, Cambridge: Cambridge University Press, pp. 13-40. 
Ponet, D. L. y Leib, E. J. (2011), «Fiduciary's Law's Lessons for Deliberative Democracy», Boston University Law Review, 91 (3), pp. 1249-1261.

Przeworski, A. (1999), «A Minimalist Conception of Democracy», en: I. Shapiro y C. Hacker-Cordón (eds.): Democracy's Value, Cambridge: Cambridge University Press. pp. 23-55.

Przeworski, A., Stokes S. C. y Manin, B. (eds.) (1999), Democracy, Accountability and Representation, Cambridge: Cambridge University Press.

Rawls, J. (2002), Justicia como equidad. Una reformulación, Barcelona: Paidós.

Richardson, H. S. (2002), Democratic Autonomy. Public Reasoning about the Ends of Policy, Oxford: Oxford University Press.

Rostbøll, C. F. (2015), «Non-domination and democratic legitimacy», Critical Review of International Social and Political Philosophy, 18 (4), pp. 424-439.

Sen, A. (2014), La idea de la justicia, Madrid: Taurus.

Simmons, J. A. (2012), «Authority», en: D. Estlund (ed.): Oxford Handbook of Political Philosophy, eOxford: Oxford University Press.

Skinner, Q. (1998), Liberty Before Liberalism, Cambridge: Cambridge University Press.

Tena, J. (2010), «Hacia una definición de la virtud cívica», Convergencia, 17 (53), pp. 311-337.

Tugendhat, E. (2008), Antropología en vez de metafísica, Barcelona: Gesdisa Editorial.

Urbinati, N. (2012), «Competing for liberty: The republican critique of democracy», American Political Science Review, 106 (3), pp. 607-621.

Van Parijs, P. (1996), «Justice and Democracy: Are they Incompatible?», The Journal of Political Philosophy, 4 (2), pp. 101-117.

Viehoff, D. (2014), «Democratic Equality and Political Authority», Philosophy and Public Affairs, 42 (4), pp. 337-375.

Viehoff, D. (2017), «The truth in political instrumentalism», Proceedings of the Aristotelian Society, 117 (3), pp. 273-295.

Viehoff, D. (2019), «Power and Equality», Oxford Studies in Political Philosophy Volume 5 (September), pp. 1-37.

White, S. (2011), «The republican critique of capitalism», Critical Review of International Social and Political Philosophy, 14 (5), pp. 561-579.

Wood, E. M. (2012), Liberty and Property, Londres: Verso Books. 
